\section{COLONIAL LABOUR AND SOCIAL DEVELOPMENT}

$\mathrm{M}$ AJOR ORDE BROWNE, labour adviser to the Colonial Secretary since 1938, has presented another of his valuable surveys, which have already covered Northern Rhodesia, the West Indies and West Africa. The latest report, which deals with recent labour conditions and recommendations for development in Ceylon, Mauritius and Malaya*, is marked by the same emphasis on the point that labour problems can be adequately analysed and met only in the context of general social development, and on the consequent need for simultaneous advance on many fronts. There is also recognition that it is often desirable to make haste slowly by means of a careful search for the most practical and comprehensive policy.

The comparative prosperity and the considerable advances in representative government have given labour problems in Ceylon very considerable political prominence, and this has been enhanced by the large-scale immigration of Tamil labourers from India. The Government of India has effectively intervened to safeguard conditions of labour for its own nationals. Ceylon also presents in fairly typical form the problems of the three distinct forms of Colonial labour-on plantations, mines and in the towns-and many of the issues that are taken up, such as the security of migrant plantation workers, the high living costs in relation to wages of urban labourers, and the problems of health and housing, have a considerably wider application in the British Colonial Empire.

On the plantations, now mainly devoted to tea, the owner-planter has steadily given place to the company, the directors of which instruct the manager from afar with limited knowledge of changing local conditions, while the immigrant Tamil labourers, returning less frequently to India, are becoming stabilized as a permanently transplanted population. Old standards and practices such as housing in 'lines' suitable only for temporary occupation, and direction of labour through headmen who recruited and controlled indentured labour, have become seriously outmoded and tend to bar further progress. At the same time, agreements with the Government of India have imposed on the estates obligations with regard to medical care and schooling that are normally regarded as falling upon Government.

Major Orde Browne asks for a new departure, slow though it may be of full achievement, based on the recognition of the new situation, so that plantation labourers and their families can live in their own communities and be provided with adequate social services, as well as housing, which would no longer be dependent on their continued employment on a particular estate, and he advocates in certain areas the creation of village settlements under Government auspices to achieve this end. Meanwhile, he suggests other means to deal with what is one of the knottiest problems associated with the plantation system, namely, that of providing adequate security of tenure for the labourer without invading the rights of the management, obviously essential in the last resort, to dismiss unsatisfactory workers. Dismissal of a plantation labourer often leaves him

* Labour Conditions in Ceylon, Mauritius and Malaya. Report of Major G. St. J. Orde Browne. (Cmd. 6423.) Pp. 114. (London: H.M. Stationery Office, 1943.) 21s. net. a landless stranger in an alien community with no home or means of support for the household which he has brought with him. In the past there has often been no alternative between dismissal and allowing unsatisfactory conduct to go unpenalized. To meet this Major Orde Browne suggests an approved scale of fines subject to the consent of the labour officer and with a right of appeal.

The Indian labour on the plantations and in the towns is now estimated to approach seven hundred thousand in all. In conjunction with growing pressure on the land occupied by the indigenous Ceylonese, this situation has produced a growing communal friction based on jealousy of the Indian workers who, in their greater dependence and amenability, have advantages from the point of view of the estate or office manager and are at the same time protected by regulations secured by the Government of India. There is little doubt that Tamil labour enjoys a privileged wage position as compared both with his fellow in India and with Ceylonese in Ceylon. This discrepancy may be fanned into a very serious political cleavage, and obviously requires, even where friction is based on misconception, prompt and persistent action in a territory where the movement towards self-government is so far advanced. Among other proposals to eliminate this serious source of friction between Ceylonese and Indians, it is recommended that the existing legislation safeguarding the conditions of employment of Indians shall be extended to apply universally.

Urban conditions in Ceylon, as so often elsewhere, are found to be less satisfactory than would be commonly supposed, since paradoxically enough social ills may be less readily perceived in towns than in even remote rural areas. The root of the difficulty is the divorce of the urban labour from that considerable degree of self-subsistence in food, housing and other domestic needs which the rural population can combine with wage-labour. Above all, house (or rather in most cases room) rents which, particularly in Colombo, for a variety of reasons including shortages and insufficient use of local materials have been very high, absorb a most disproportionate amount of wages, the real value of which are in consequence far less than those of the rural labourer. A recent inquiry revealed that the incomes of the lowest paid workers in Ceylon, even when in continuous employment, were insufficient to maintain a barely adequate standard of nutrition and shelter. In this connexion the Mauritius report refers to a salutary example, in the Bell Village estate, of an impulsive and ill-conceived housing development which rapidly became derelict owing to insulficient investigations into siting, constructional and other requirements.

A similar need to avoid too rapid an establishment of Western forms, as distinct from pressing on towards Western standards, is apparent in the field of labour organizations. Trade unionism in Ceylon is embryonic and finds little sustained support among workers, in either a consciousness of solidarity or a capacity for organization. The would-be trade union organizer has too often been an outsider, sometimes disaffected, who sees a career and way to achieve some degree of personal power through the urging of his notions of the methods and objectives of unionization on inexperienced groups of workers. The social implications are clear. Union organization as a means of raising living standards and working efficiency through collective bargaining can only be satisfactorily developed pari passu with the advance in education 
and in a genuine sense of community of enlightened interests among the workers themselves. While the dangers that the vulnerability of unorganized workers may be abused are real, the activities of ephemeral and sometimes bogus labour organizations which do not command the loyalty of workers or serve their genuine interests may be ultimately as harmful to their welfare and working conditions. A significant instance of often serious indifference among the people themselves to improvements in working conditions and hours, when immediate money returns are held to be paramount, was found among Chinese brick workers in Malaya, who refused to agree to the curtailment of an 84-hour week.

The difficulties in applying Western standards of social security in Colonial territories like Ceylon and Malaya, where even under conditions of comparative prosperity national income and Government financial resources are so limited, becomes very plain. It would have been interesting in this context to have learnt how far work on plantations and in the towns has undermined the solidarity of family group life. These groups frequently provide their own mutual insurance and spreading of risks under peasant conditions. But they have proved very vulnerable in many territories to the introduction of personal incomes from wage labour. Their protection against rapid disintegration while alternative forms of group organization or social services are developed in their place poses a serious problem in applied sociology.

The vicious circle of poverty, under-nourishment, poor health and low output of labour, which does not in consequence earn an adequate purchasing power, is more than generally obvious in Mauritius. The attempt to break this circle should, as Major Orde Browne emphasizes, underlie all development plans and in particular it should include full attention to the need for improving the feeding and thereby the health of the rising generation through the provision of school meals and other means of raising nutritional standards.

As has been indicated, these reports emphasize the need for a comprehensive view of the context of Colonial labour problems. Of the many lessons to be learned there is perhaps special need for emphasis on one which does not find direct expression in the reports themselves. Major Orde Browne alludes at every turn to the lack of adequate data for the analysis of the actual situations and confident formulation of policy. $\mathrm{He}$ makes some recommendations for additional appointments and duties in the Labour Departments; but the complexity of the problems and the many gaps in existing information all point to the need for the earliest possible programme for social surveys in the Colonial Empire by trained investigators. Reports such as these leave little doubt as to the general nature of the problems, but for the proper selection and integration of development projects a more adequate and comprehensive body of empirical data is needed. We have so far in the British Empire paid too little attention to the development of applied sociology, to the training of field workers and the organization of comprehensive investigations. Much could be learned from substantial American experience and achievements in this field. The latter have been remarkable for their investigations and the planning of remedial projects in backward or depressed areas. Colonial development offers one among several opportunities for the fruitful application of the social sciences, and valuable work of this kind is beginning in the West Indies. The provision and harnessing o a sufficient body of workers, trained in social anthro pology, survey methods and rural economics needec for this task are long overdue. Such training anc organization will take time, and the earliest star should be made in preparing for them immediately after the War.

DARYLL FORDE.

\section{MODERN DRUGS AND TROPICAL DISEASES}

WHEN primitive man first began to use tools, he presumably employed stones or branches which he found fortuitously in shapes suitable for his pur. pose. Later he learnt how to fashion implements by simple modifications of pre-existing material, and in recent years he has built the vast and complicated machines which now sustain our moderm civilization. A similar, but less extensive, progress can be seen in the realm of therapeutics. For long ages medical men were restricted to simple herbal and mineral remedies; then steps were taken to isolate the active alkaloids and other principles and to make simple chemical modifications in them; lastly, since the days of Ehrlich and his predecessors, therapy has come to rely more and more on compounds synthesized especially for this purpose by the organic chemist, on lines previously unknown in the vegetable, animal, or mineral worlds. This modern state of drug therapy is well illustrated by a discussion which was held at the Royal Society of Tropical Medicine and Hygiene on July 14 on "Modern Drugs in the Prevention and Treatment of Tropical Diseases". The only drug of natural origin which was mentioned was quinine, the purified alkaloid from cinchona bark. All the other substances discussed were compounds which have been prepared for the first time not more than ten or twenty years ago.

The chief speaker was Colonel S. P. James. $H_{\theta}$ began by referring to the great contributions made to our knowledge of the subject by the late Prof. Warrington Yorke, whose recent untimely death was also deplored by other speakers. Yorke was the first to examine scientifically by controlled experiments the practice of trying to sterilize a malarial infection by giving quinine in very large doses for a long period. He made three outstanding observations. The first was that quinine, however and whenever it is given, does not prevent infection from the bite of mosquitoes carrying malaria. The second was that, at the onset of the primary attack, quinine has no action at all until a good many parasites are present in the peripheral blood. The third was that quinine, however and whenever it is given, does not prevent malaria from relapsing. The therapeutic value of quinine and of the other main antimalarial compound mepacrine ('Atebrin') lies in their power to prevent the infection from developing into the clinically recognizable disease (suppressive treatment or prophylaxis) and to cut short the actual attacks of the disease (curative treatment). Although it is not possible to kill off all the malaria parasites in the body, and although, when treatment has ceased, they will sooner or later reappear causing a relapse, com. plete cure will eventually be produced by the develop. ment of immunity in the patient after a number of attacks have occurred. To control the clinical manifestations of the disease in this way, quite small 